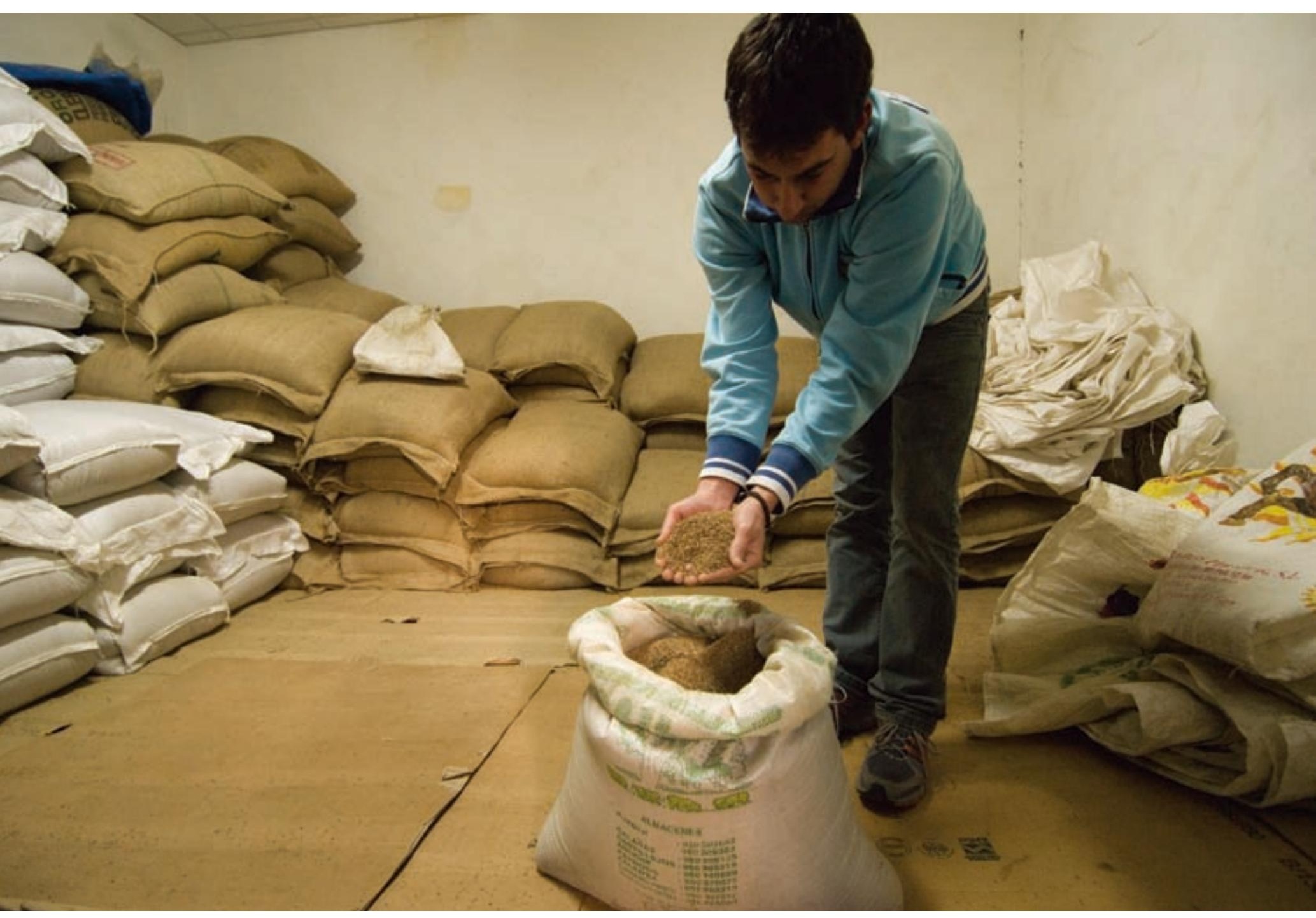

Fábrica de Anisados Arenas. Almacén de matalahúga (Zalamea la Real). Foło: Juan Carlos Cazalla, IAPH 


\section{La fabricación de aguardiente}

Isabel Aguilar Majarón, antropóloga. Aniceto Delgado Méndez, Centro de Documentación del IAPH
Según el diccionario de la Real Academia Española de la Lengua, el aguardiente es una "bebida espiritosa, que por destilación, se saca del vino y otras sustancias" como frutas, semillas como el centeno, la cebada, las bayas de enebro, la cereza, el anís, u otras. El aguardiente por tanto es el nombre genérico de bebidas alcohólicas destiladas, de entre 40 y 45 grados, que pueden ser bebido, ya sea puro, añejado, aromatizado o mezclado.

En lo que respecta a la provincia de Huelva, será a partir del siglo XVIII cuando encontramos documentos que nos indican la existencia de diferentes fábricas de aguardiente, tanto en la sierra de Huelva (principalmente en Aracena) como en la Tierra Llana. En esta época, el destino del aguardiente de Huelva era fundamentalmente Cádiz, lugar desde el que salia hacia las posesiones españolas en ultramar.

En la comarca del Andévalo la producción en un principio se limitaba a la Puebla de Guzmán y su destino eran tanto la Palma del Condado como el Aljarafe sevillano. Posteriormente, en el siglo XIX se fundará la primera fábrica de aguardiente en la localidad de Zalamea la Real. La tradicional elaboración del aguardiente en esta localidad, a diferencia de lo que podiamos pensar, es anterior a la presencia inglesa, si bien la explotación de las minas y toda la actividad generada en torno a ellas supusieron un aumento considerable de la demanda.

Además de la fábrica de aguardiente de las Tres Casas creada en 1940, y Anisados Arenas, fundada en 1942, existían en Zalamea la firma Herederos de J. González, S.L. y la de los Hermanos Martín Rivas (1905), ambas sin actividad en la actualidad.

Junto a las fábricas asentadas en Zalamea, principal productor de aguardiente de la comarca, también encontramos ejemplos en Valverde del Camino, Alosno, la Puebla de Guzmán, y la desaparecida fábrica de "San Matías" en Villanueva de los Castillejos.

Según el proceso de fabricación del aguardiente, en esta comarca encontramos dos tipologías: la producción mediante desti- lado o cocido y en frío. Dentro de las fábricas que continúan elaborando el aguardiente por destilación, se encuentran "Anisados Zarza Mora", en Valverde del Camino, y "Anisados El Pilar" y "Anisados Arenas", en Zalamea la Real. Mientras que las fábricas que lo realizan en "frío" son "Anisados Rebollo" en Alosno y "Antonio Ponce e Hijos S.L.", que comercializa distintas marcas en la localidad de Puebla de Guzmán.

Para la elaboración por destilación, en primer lugar se introduce la leña de encina en el horno que está debajo de la caldera, a continuación se carga la caldera con matalahúga, alcohol y el agua, para posteriormente cerrarla herméticamente y encender el fuego.

Pasadas unas cuatro horas empieza a hervir la cocción, y sale el primer líquido. Este se le denomina "cabeza" y se desprecia, porque es muy amargo y fuerte. A partir de aquí, y manteniendo la caldera a fuego lento, es cuando sale el aguardiente que se utiliza para la venta y cuya denominación es conocida como el "cuerpo".

Posteriormente, el resultado del proceso anterior se vierte en la batidora para darle la graduación y para ello se utiliza agua de pozo, ya que debe ser lo más pura posible. Realizada la graduación se miden los grados teniendo en cuenta la blancura que adquiere el líquido y después se prueba, antes de que el aguardiente pase a los depósitos donde se macera por decantación y sea embotellado.

El otro proceso de fabricación es conocido como en frío, para ello lo esencial son los ingredientes utilizados y su mezcla en la batidora, elemento que sustituye al alambique y el proceso del cocción con la matalahúga.

Junto a la eliminación del destilado y la mezcla de los elementos utilizados en este proceso, lo que caracteriza la fabricación del aguardiente en frío son los porcentajes de ingredientes utilizados y que forman parte del secreto de cada fabricante. Los ingredientes 
El aguardiente sigue trazando líneas

que nos llevan a tratar aspectos

tales como las culturas del trabajo,

los rituales festivos, la alimentación, y toda una serie de elementos

dinámicos que proyectan escenas

de formas de ser y sentir de una

determinada comunidad

básicamente son la esencia de matalahúga o la flor de la badiana, a veces separadas y en ocasiones mezclándolas, alcohol de melaza (de caña de azúcar), y agua de la red municipal, pasada antes por el filtro para quitarle el sabor del cloro y otras impurezas.

La mezcla del compuesto se realiza en la batidora, primero se echa el agua y después el alcohol, cuando ya tiene un volumen importante de alcohol se añade la esencia de matalahúga o badiana. Progresivamente se mezcla el agua, el azúcar y el alcohol, todo seguido uno después de otro y la batidora continuamente está mezclando los ingredientes. Cuando ya está todo bien batido se miden los grados para controlar la graduación del alcohol y después se pasa al filtrado y seguidamente el líquido va a parar a los diferentes depósitos de almacenamiento.

En la provincia de Huelva, al contrario de lo que ocurre en la provincia de Sevilla o en otros lugares, la producción del aguardiente no se realiza con el alcohol de vino o alcohol de bodega, sino con alcohol de melaza, proveniente de la caña de azúcar.

La actividad productiva del anisado, por tanto, en la comarca del Andévalo, ha modelado con el paso de los años diferentes estrategias encaminadas a una producción familiar e industrial que si bien no han producido en términos cuantitativos valores diferenciales sí que ha permitido la adaptación de determinados espacios a una actividad que ha ido consolidándose en las localidades de Alosno, Zalamea la Real, Puebla de Guzmán y Valverde del Camino.

Aunque no podemos hablar de una especialización del sector, debido entre otras razones a la estacionalidad y al cada vez menor consumo de la producción, sí podemos afirmar que el aguardiente ha sido y sigue siendo (con diversas transformaciones) un elemento de enorme relevancia para contextualizar el sector industrial en este territorio andaluz. En este sentido tampoco podemos relegar la importancia que estas fábricas han tenido durante determinados momentos históricos y la capacidad de adaptación a los diferentes momentos por los que ha oscilado el sector.

La importancia de este producto no vendrá definida por la existencia de fábrica o no, sino por ser un referente cultural que dificilmente encuentra límites que lo comprima. El aguardiente será elaborado, utilizado en repostería, bebido, y sobre todo vivido. Lejos de plantear hipótesis sobre su permanencia en la cultura andaluza,

el aguardiente sigue trazando líneas que nos llevan a tratar aspectos tales como las culturas del trabajo, los rituales festivos, la alimentación, y toda una serie de elementos dinámicos que proyectan escenas de formas de ser y sentir de una determinada comunidad.

Asociado a determinadas actividades como el trabajo en el campo o la mina, el consumo del aguardiente adquiere además una importante significación en determinados tiempos rituales tales como las romerías o las fiestas de cruces de mayo. Además es necesario relacionar el uso que se hacía de este producto con fines terapéuticos y medicinales, pues del mismo se decía que calmaba los dolores de barriga o el dolor de muelas.

En la actualidad la fabricación de aguardiente no pasa por un buen momento, y esto se debe en gran medida a la bajada en el consumo, la existencia de grandes fábricas con las que dificilmente pueden competir, la desaparición de los conocimientos transmitidos de padres a hijos, el aumento en los costes y los altos impuestos que deben pagar los productores. Asistimos por tanto a nuevos contextos donde los interrogantes sobre el futuro de esta actividad aumentan con el paso del tiempo y donde las respuestas son dificilmente imaginables.

\section{En la web}

\section{DIPUTACIÓN DE HUELVA}

www.diphuelva.es

Podemos acceder a un indice de los municipios de la provincia de Huelva donde encontramos información específica de cada uno de ellos: información general, ubicación, patrimonio cultural y artístico y otros datos de interés como enlaces, servicios y galerias fotográficas.

\section{ASOCIACIÓN PARA EL DESARROLLO RURAL DEL ANDÉVALO OCCIDENTAL}

www.adrao.com

Ofrece información detallada sobre los proyectos de la asociación, así como un enlace por cada municipio de la comarca, con noticias, imágenes, datos de interés y actividades especificas de cada localidad.

\section{MANCOMUNIDAD DE MUNICIPIOS DEL ANDÉVALO}

www.mmandevalo.org

Encontramos información sobre la comarca del Andévalo en imágenes, con acceso a la información que ofrecen los ayuntamientos de cada uno de los municipios, principalmente actualidad sobre sus actividades y servicios.

\section{SAN BENITO ABAD. EL CERRO DEL ANDÉVALO}

www.sanbenitoelcerro.com

Web dedicada al patrón de esta localidad con acceso a los festejos que se celebran a lo largo del año, trajes, bailes, cantes y la ermita. También encontramos información de la romería y un glosario de términos específicos.

\section{MUSEO ETNOGRÁFICO DEL CERRO DEL ANDÉVALO}

www.museo.elcerrodeandevalo.net

Web dedicada a la historia del edificio y su diversidad funcional a lo largo del tiempo. También muestra su contenido distribuido en tres salas con imágenes ampliables y explicación detallada de la exposición. Finalmente, encontramos un enlace a las Actividades que realiza el museo: cursos de verano en la Universidad de Huelva entre otras. 